OTOLOGY

\title{
From CT scanning to 3D printing technology: a new method for the preoperative planning of a transcutaneous bone-conduction hearing device
}

\author{
Dalla TC alla stampante 3D: un metodo innovativo per la pianificazione chirurgica \\ di una protesi a conduzione ossea transcutanea
}

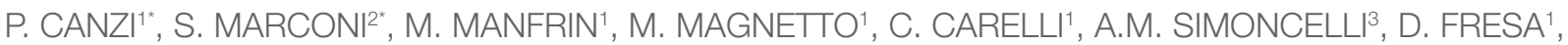 \\ M. BELTRAME' ${ }^{1}$ F. AURICCHIO², M. BENAZZO'
}

${ }^{1}$ Department of Otorhinolaryngology, University of Pavia, Foundation IRCCS Policlinico "San Matteo", Pavia, Italy; ${ }^{2}$ Department of Civil Engineering and Architecture, University of Pavia, Italy; ${ }^{3}$ Department of Diagnostic Radiology and Interventional Radiology and Neuroradiology, University of Pavia, Foundation IRCCS Policlinico "San Matteo", Pavia, Italy

"These authors contributed equally to this article

\section{SUMMARY}

The aim of the present study was to assess the feasibility and utility of 3D printing technology in surgical planning of a transcutaneous boneconduction hearing device (Bonebridge $\left.{ }^{\circledR}\right)(\mathrm{BB})$, focusing on the identification of the proper location and placement of the transducer. 3D printed (3DP) models of three human cadaveric temporal bones, previously submitted to CT scan, were created with the representation of a topographic bone thickness map and the sinus pathway on the outer surface. The 3DP model was used to detect the most suitable location for the BB. A 3DP transparent mask that faithfully reproduced the surface of both the temporal bone and the 3DP model was also developed to correctly transfer the designated BB area. The accuracy of the procedure was verified by CT scan: a radiological marker was used to evaluate the degree of correspondence of the transducer site between the 3DP model and the human temporal bone. The BB positioning was successfully performed on all human temporal bones, with no difficulties in finding the proper location of the transducer. A mean error of $0.13 \mathrm{~mm}$ was found when the transducer site of the 3DP model was compared to that of the human temporal bone. The employment of 3D printing technology in surgical planning of BB positioning showed feasible results. Further studies will be required to evaluate its clinical applicability.

KEY WORDS: 3D printing• Bonebridge $\bullet$ Implantable hearing aid • Bone conduction implant $\bullet$ Surgical planning

\section{RIASSUNTO}

Il presente studio ha lo scopo di descrivere un'innovativa metodica che mediante l'utilizzo della stampante 3D permetta una più agevole pianificazione preoperatoria del posizionamento di una protesi a conduzione ossea transcutanea (Bonebridge $\left.{ }^{\circledR}\right)(B B)$. Tre ossa temporali umane conservate in formalina sono state sottoposte a studio radiologico TC ad alta risoluzione al fine di consentire la realizzazione dei corrispettivi modelli $3 D$, utili all'identificazione della corretta ubicazione del BB. Ciascun modello $3 D$ di temporale umano era caratterizzato dalla rappresentazione sulla sua superficie sia di una mappa topografica a colori rappresentativa dello spessore dell'osso temporale, sia del seno sigmoideo nel suo decorso. Un secondo modello $3 D$ trasparente ("template") è stato stampato con lo scopo di riprodurre fedelmente la superficie dell'osso temporale, in modo da trasferire l'area designata al posizionamento del BB dal modello 3D all'osso temporale. L'accuratezza della procedura è stata quindi verificata attraverso un successivo studio TC mirato alla comparazione del sito di posizionamento del device tra modello $3 D$ e osso temporale umano. In tutti e tre i casi è stato possibile posizionare correttamente la protesi, senza riscontrare difficoltà nell'identificazione del sito di impianto. Nella valutazione della corrispondenza del sito designato tra modello $3 D$ e osso temporale è stato riscontrato un errore medio di $0.13 \mathrm{~mm}$. L'utilizzo della tecnologia di stampa $3 D$ nella pianificazione chirurgica del posizionamento del BB ha mostrato risultati incoraggianti; ulteriori studi saranno necessari per appurarne l'applicabilità clinica.

PAROLE CHIAVE: Stampante $3 D \bullet$ Bonebridge $\bullet$ Protesi acustica impiantabile $\bullet$ Protesi a conduzione ossea $\bullet$ Pianificazione chirurgica

Acta Otorhinolaryngol Ital 2018;38:251-256 


\section{Introduction}

During the last years, the continuous technological progress of 3D printing has given new and fascinating applications in the medical and surgical fields, with interesting applications in the otologic surgery as well. 3D printing refers to the process of creating 3D objects starting from a virtual 3D model. The growing interest in the medical field regarding this new kind of technology is linked to the possibility of producing anatomical models that are useful to surgical training and operative planning ${ }^{1-6}$. The Bonebridge ${ }^{\circledR}(\mathrm{BB}$, Med-El, Innsbruck, Austria) is a semi-implantable transcutaneous bone-conduction implant, whose effective element ("Bone Conduction Floating Mass Transducer" or BCFMT) is implanted subcutaneously, without any continuity with the outside ${ }^{7}$. Compared to percutaneous bone-conduction implants, the BB has a decreased risk of skin adverse events without the audiological limitations that characterise passive transcutaneous hearing systems due to dampening effects of the skin ${ }^{78}$. The surgical procedure required for placement of the BC-FMT is challenging because of the physical dimensions required: $8.7 \mathrm{~mm}$ in thickness, $15.8 \mathrm{~mm}$ in diameter and $23.8 \mathrm{~mm}$ between anchor holes ${ }^{78}$. Surgical positioning requires sufficient bone thickness and a relatively flat surface in order to fix the device into the cortical bone through the anchoring screw, at the extremity of the two lateral rigid wings. Currently, the optimal BB position is chosen by simulating the placement preoperatively through the creation of a 3D image based on the CT of the patient, by manual measurements of the bone thickness in separate two-dimensional axial, coronal or sagittal CT slices. Then the surgeon, according to the anatomic pattern of each patient, identifies the planned position on the temporal bone using as reference specific anatomical landmarks. Based on the most recent literature, different surgical and radiological strategies have been proposed to facilitate positioning of the $\mathrm{BB}^{9-13}$. The aim of the present study was to report an innovative technique employing $3 \mathrm{D}$ printing technology, with the purpose of making positioning of the $\mathrm{BB}$ easier and safer. The execution modalities and results in a cadaveric feasibility study will be discussed.

\section{Materials and methods}

\section{Construction of 3DP models}

Three temporal bones were submitted to a high-resolution CT scan (slice thickness $0.5 \mathrm{~mm}$ ). The images allowed printing the corresponding 3D models (Fig. 1) characterised by the following innovations: (1) representation on the 3DP model external surface of a topographic map indicating the thickness of the underlying bone; (2) rep- resentation of the sigmoid sinus pathway on the external surface of the 3DP model. The resulting model was 3DP using a Projet 460Plus (3D Systems), which is based on binder jetting technology: the printer works with chalklike powder cured layer by layer using a binder and ink colours. The printer has a layer thickness resolution of 100 $\mu \mathrm{m}$ and a chromatic resolution of more than 2.8 million of colours, and is thus perfectly suitable for the present application. A second 3DP model ("template") (Figs. 2, 3A) was printed based on the CT images of the cadaveric temporal bone and employing specific algorithms to obtain a transparent "mask" of $1 \mathrm{~mm}$ of thickness. The template was specular to the human bone surface, perfectly reproducing all radiological and anatomical landmarks (posterior wall of the external auditory canal with the Henle's spine, mastoid tip, zygomatic process of the temporal bone with the temporal line). Consequently, the template was developed to be univocally lodged on the specimen and allowing only one possible placement. The purpose of the template was to allow the transfer of the area designated for the BC-FMT from the 3DP model to the human temporal bone. The template was 3DP using a Form2 (FormLabs) printer, based on stereo-lithographic technology, using a layer thickness resolution of $25 \mu \mathrm{m}$. A transparent photopolymer was used for prototyping to ensure visibility of the underlying thickness map.

\section{Surgical planning and surgical procedure}

The best BC-FMT position was detected for each 3DP temporal bone model taking into consideration bone thickness (through the topographic map), flatness of the bone surface and surgical landmarks (sigmoid sinus, external acoustic meatus, mastoid tip). After positioning the template on the 3DP model, the site chosen for the BC-FMT was marked on the template using the T-sizer (Fig. 3B). The marked area was drilled using a precision drill press with a $16 \mathrm{~mm}$ bit (Fig. 3C), hence the template was suitable for the surgical procedure (Fig. 3D). The drilled template was placed on the human temporal bone to report the BC-FMT site (Fig. 4). BB implant surgery was performed according to the literature in order to place the BC-FMT into the bony well and fix the implant with anchor screws (Fig. 5).

\section{Accuracy of BC-FMT surgical placement}

To verify the accuracy of surgical placement, a radiological marker (a lead ball of a $0.2 \mathrm{~mm}$ diameter) was placed on the centre of the BC-FMT site of both the 3DP model and human temporal bone (Fig. 6), using the 3DP template for a precise positioning. Both 3DP model and human temporal bone were submitted to CT scan and the 


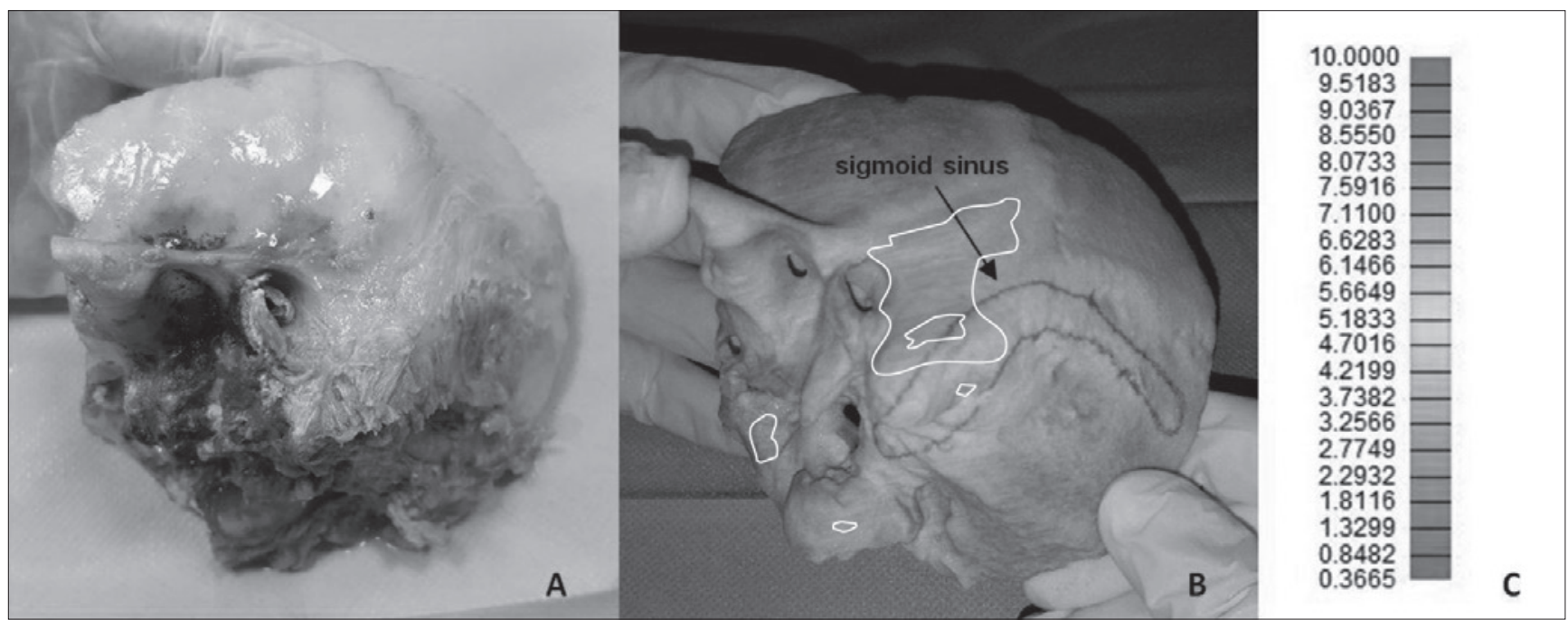

Fig. 1. Human temporal bone (A). 3DP temporal model with topographic bone thickness map and sigmoid sinus pathway representation (B). Legend of the topographic bone thickness map (example: white line area represents a $10 \mathrm{~mm}$ bone thickness) (C).

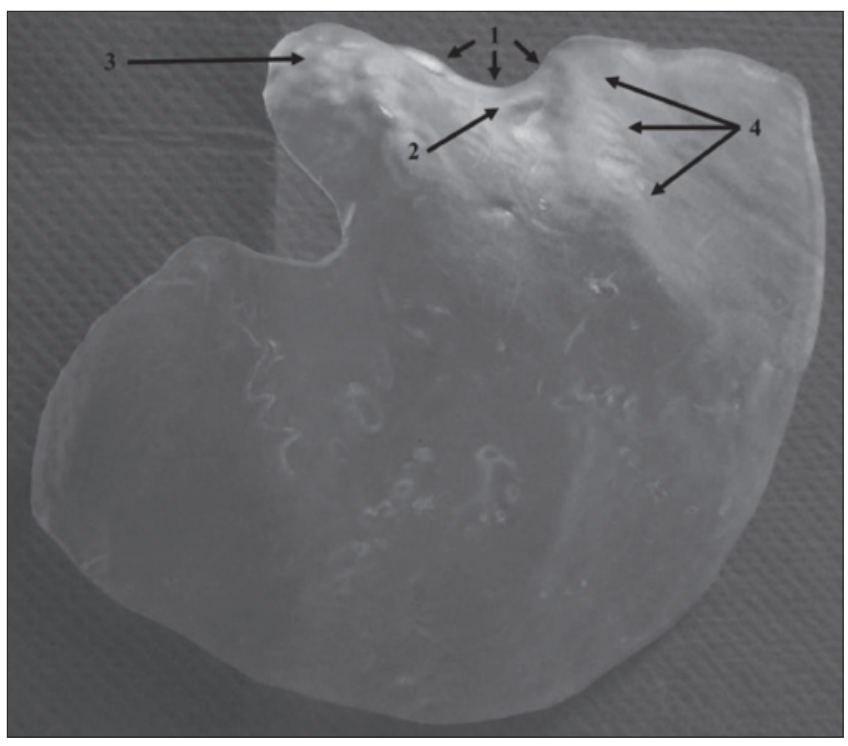

Fig. 2. 3DP template with the anatomical landmarks that allow its proper lodging on the temporal bone. 1: posterior wall of the external auditory canal; 2: Henle's spine; 3: mastoid tip; 4: temporal line.

distance of the radiological marker to specific anatomical landmarks was measured and compared to evaluate the degree of correspondence (Table I).

\section{Results}

In all the three cases, BC-FMT positioning was successfully performed. The optimal placement was always identified at the sino-dural angle. Dural decompression was not needed in any case to allow BC-FMT positioning. The sigmoid sinus
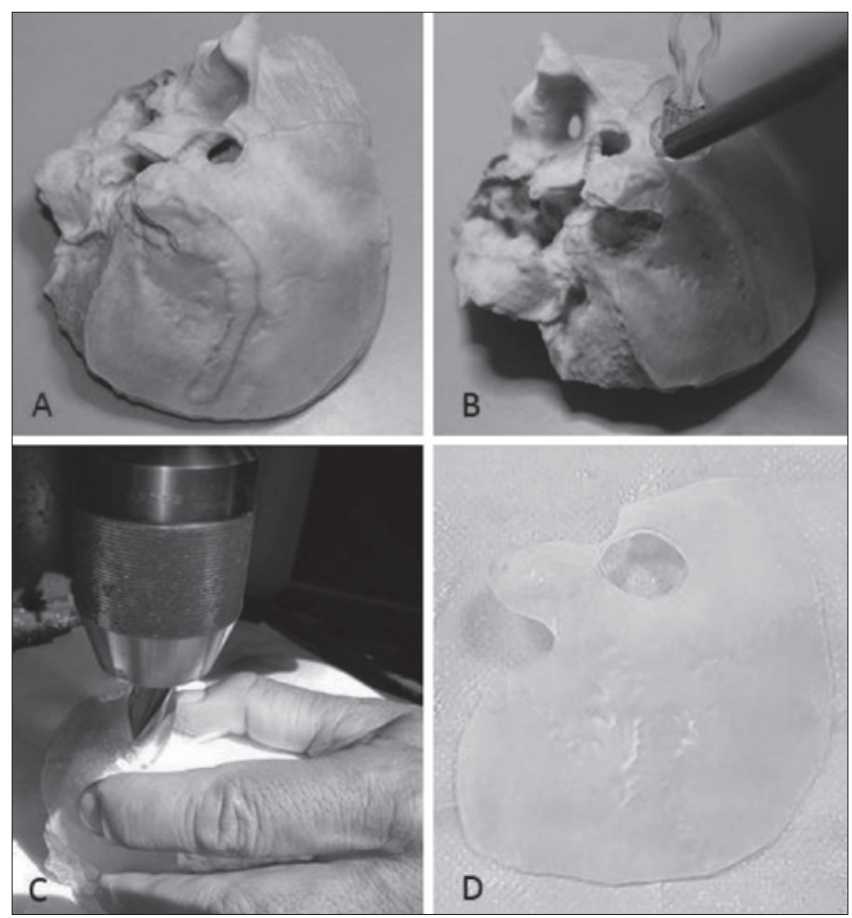

Fig. 3. The transparent template positioned over the 3DP model (A). Marking the BC-FMT area with the T-sizer on the template (B). 3DP template drilling in correspondence of the BC-FMT location (C). Template with surgical guide for BC-FMT positioning (D).

was never subjected to surgical decompression. The procedure was performed with a mean time of 21 minutes, without difficulties in finding the proper BC-FMT site. A mean error of $0.13 \mathrm{~mm}$ was found when the BC-FMT site of the 3DP model was compared to that of the human temporal bone. 


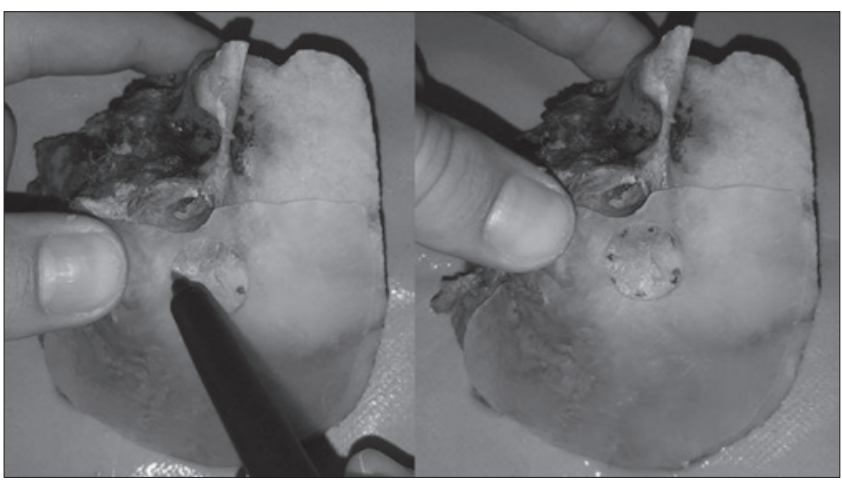

Fig. 4. Marking of the BC-FMT positioning area on the human temporal bone with the drilled template.

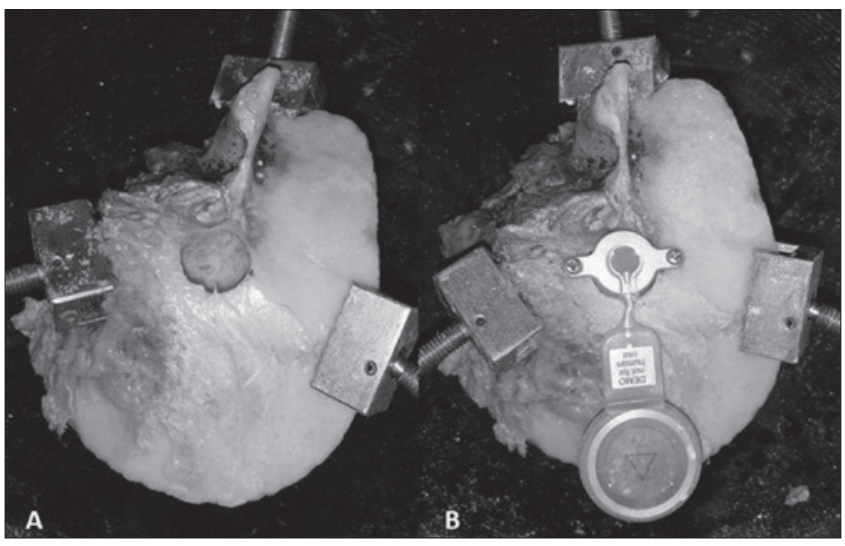

Fig. 5. Bony well for BC-FMT placement on human temporal bone (A). BCFMT placement and fixation with both anchoring screws (B).

\section{Discussion}

Current selection criteria for BB include conductive bilateral hearing loss, mixed bilateral hearing loss and single side deafness with normal hearing in the opposite ear ${ }^{8}$. Nowadays, only two surgical approaches are still utilised: the retrosigmoid approach and the presigmoid one. Most commonly reported in literature, the presigmoid technique concerns BC-FMT placement in the sino-dural angle considering its anatomical limits: the sigmoid sinus, the posterior wall of the external auditory canal and the dura ${ }^{8}$. $\mathrm{BB}$ implantation is a demanding procedure requiring general anaesthesia and a skilled surgeon. Surgical technical difficulties mainly derive from pre-operative planning: choosing the most suitable site to place the BC-FMT (sufficient bone thickness and relatively flat surface), avoiding lesions of nearby anatomical structures and then finding the defined location on the temporal bone of the patient ${ }^{8}$. Up to now, BC-FMT placement is a difficult cognitive task for the surgeon in terms of three-dimensional spa- tial reconstruction of the preoperatively planned position on CT. In fact, the three-dimensional information of a CT scan is usually displayed as series of two-dimensional images, and therefore a comparison between the three radiological planes is required to conceive a three-dimensional evaluation of the temporal bone. Furthermore, the two-dimensional information provided by the radiological scans is not adequate to understand whether the surface of the bone is regular or flatter. The identification of the proper location of the BC-FMT, relying only on the radiological images, could be challenging because the best surgical positioning requires a three-dimensional study of the temporal bone considering its thickness, surface and all anatomical landmarks.

Another laborious issue is localisation of the planned position on the temporal bone, without losing precision ${ }^{8}$. Newly acquired scientific studies have been reported in literature, aimed at overcoming the aforementioned surgical procedure limits. In 2015 , Wimmer et al. ${ }^{9}$ first applied a topographic bone thickness map in the preoperative planning for the BB positioning in seven patients, although the thickness map was only radiologically elaborated and required the identification of anatomical landmarks to detect the BB location on the patient. In 2014, the Japanese Kyushu and Shinshu Universities ${ }^{10-12}$ and later the St. Thomas Hospital in London ${ }^{13}$, developed a 3DP template to surgically identify the BC-FMT site previously planned on CT. According to the authors, the template fulfilled the issue of how to find a defined anatomical area detected in CT on the temporal bone, while the remaining restrictions were still unresolved. In our experience, a 3DP temporal bone model was developed allowing intuitive preoperative assessment of the BB placement. In particular, the choice of the proper location of the device was much more intuitive and practical in comparison to radiological preoperative planning due to the employment of a three-dimensional model that is able to define all anatomical landmarks, regularity of the bone surface and thickness of the underlying bone. In all three cases, quick identification of the appropriate BC-FMT position was accomplished. Compared with the study of Wimmer et al. ${ }^{9}$, the 3DP model of the temporal bone added the advantage to define where the bone surface was the flattest and thus the most suitable for BC-FMT screw anchoring, a procedure that is not intuitive if based on a bi-dimensional CT image. Finally, in all cases the transparent template enabled safe identification of the planned BC-FMT position on the temporal bone, previously localised on the 3DP model, with a mean error of $0.13 \mathrm{~mm}$. A critical analysis of our study, supports the need of an optimal 


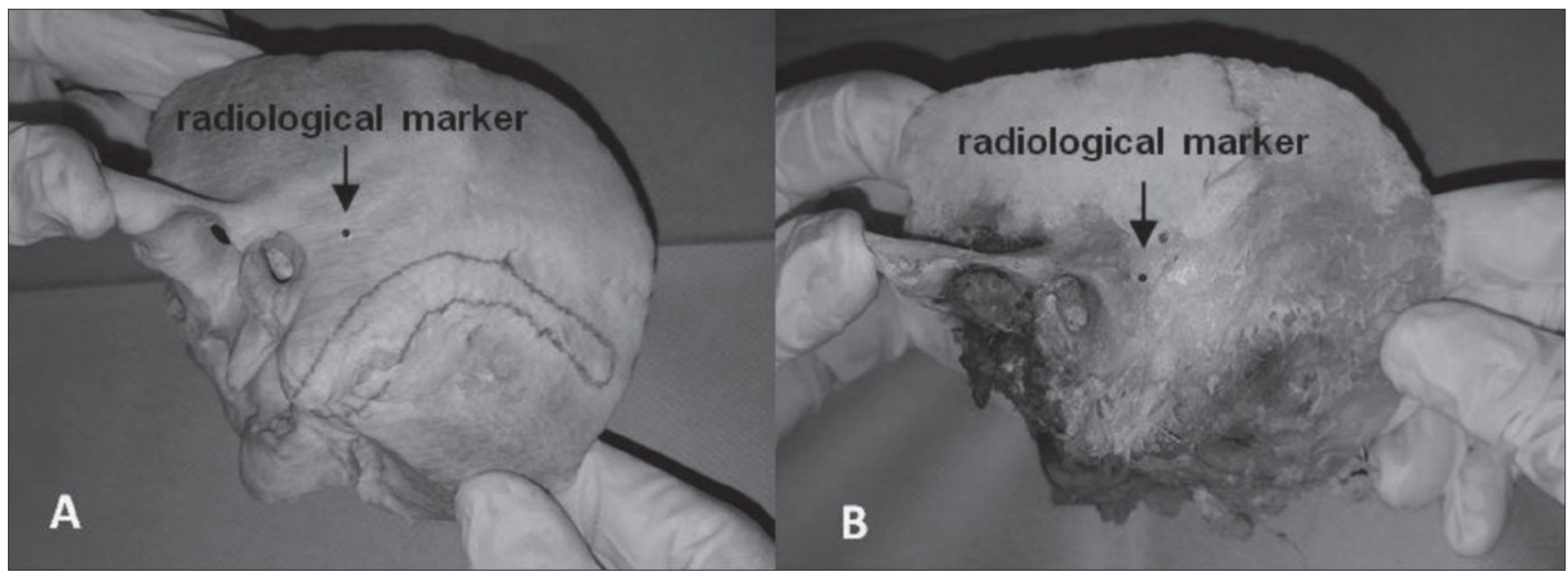

Fig. 6. Radiological marker positioned on the 3DP model (A) and on the human cadaveric bone (B).

Table I. Distance of the radiological marker to specific anatomical landmarks in the three radiological planes on the 3DP model and the human temporal bone.

\begin{tabular}{|c|c|c|c|}
\hline & 3D model & Human model & Radiological plane \\
\hline \multirow[t]{3}{*}{ Specimen 1} & $46.84 \mathrm{~mm}$ & $46.51 \mathrm{~mm}$ & Axial \\
\hline & $19.41 \mathrm{~mm}$ & $19.19 \mathrm{~mm}$ & Coronal \\
\hline & $31.38 \mathrm{~mm}$ & $31.26 \mathrm{~mm}$ & Parasagittal \\
\hline \multirow[t]{3}{*}{ Specimen 2} & $43.51 \mathrm{~mm}$ & $43.41 \mathrm{~mm}$ & Axial \\
\hline & $22.61 \mathrm{~mm}$ & $22.92 \mathrm{~mm}$ & Coronal \\
\hline & $47.85 \mathrm{~mm}$ & $47.93 \mathrm{~mm}$ & Parasagittal \\
\hline \multirow[t]{3}{*}{ Specimen 3} & $58.66 \mathrm{~mm}$ & $58.66 \mathrm{~mm}$ & Axial \\
\hline & $29.15 \mathrm{~mm}$ & $29.18 \mathrm{~mm}$ & Coronal \\
\hline & 31.13 mm & $31.16 \mathrm{~mm}$ & Parasagittal \\
\hline
\end{tabular}

decrease of template dimensions to allow its feasibility during the clinical phase of our work. A minimally invasive approach considering soft tissue management represents a key point that should be clarified for the application of our 3D printing-guided method on the patient.

\section{Conclusions}

According to the most recent literature, there is a growing interest in the use of 3D printing for ENT surgical decision-making. In our preliminary experience, the employment of 3D printing technology in the surgical planning of BB positioning showed feasible results and was a practical and intuitive alternative to the current methods described in literature. Further studies will be required to evaluate its clinical applicability, and in particular in overcoming the limits related to soft tissues.

\section{References}

1 Da Cruz MJ, Francis HW. Face and content validation of a novel three-dimensional printed temporal bone for surgical skills development. J Laryngol Otol 2015;129(Suppl 3S):23-9.

2 Hochman JB, Rhodes C, Wong D, et al. Comparison of cadaveric and isomorphic three-dimensional printed models in temporal bone education. Laryngoscope 2015;125:2353-7.

3 Kozin ED, Remenschneider AK, Cheng S, et al. Three-dimensional printed prosthesis for repair of superior canal dehiscence. Otolaryngol Head Neck Surg 2015;153:616-9.

4 Longfield EA, Brickman TM, Jeyakumar A. 3D Printed Pediatric temporal bone: a novel training model. Otol Neurotol 2015;36:793-5.

5 Rose AS, Kimbell JS, Webster CE, et al. Multi-material 3D models for temporal bone surgical simulation. Ann Otol Rhinol Laryngol 2015;124:528-36.

6 Rose AS, Webster CE, Harrysson OL, et al. Pre-operative simulation of pediatric mastoid surgery with $3 D$-printed 
temporal bone models. Int J Pediatr Otorhinolaryngol 2015;79:740-4.

7 Sprinzl G, Lenarz T, Ernst A, et al. First European multicenter results with a new transcutaneous bone conduction hearing implant system: short-term safety and efficacy. Otol Neurotol 2013;34:1076-83.

8 Sprinzl GM, Wolf-Magele A. The Bonebridge Bone Conduction Hearing Implant: indication criteria, surgery and a systematic review of the literature. Clin Otolaryngol 2016;41:131-43.

9 Wimmer W, Gerber N, Guignard J, et al. Topographic bone thickness maps for Bonebridge implantations. Eur Arch Otorhinolaryngology 2015;272:1651-8.
10 Cho B, Matsumoto N, Mori M, et al. Image-guided placement of the Bonebridge without surgical navigation equipment. Int J Comput Assist Radiol Surg 2014;9:845-55.

11 Takumi Y, Matsumoto N, Cho B, et al. A clinical experience of "STAMP" plate-guided Bonebridge implantation. Acta Otolaryngol 2014;134:1042-6.

12 Matsumoto N, Takumi Y, Cho B, et al. Template-guided implantation of the Bonebridge: clinical experience. Eur Arch Otorhinolaryngol 2015;272:3669-75.

13 Pai I, Rojas P, Jiang D, et al. The use of $3 D$ printed external and internal templates for Bonebridge implantation - technical note. Clin Otolaryngol 2017;42:1118-20.

Received: Februray 9, 2017 - Accepted: August 22, 2017

Address for correspondence: Pietro Canzi, University of Pavia, Department of Otorhinolaryngology, IRCCS Policlinico San Matteo Foundation, viale Camillo Golgi 19, 27100 Pavia, Italy. Email: pietro.canzi@unipv.it 